\title{
MEMÓRIA, CINEMA E FOTOGRAFIA: reflexões sobre o filme Ulysse, de Agnès Varda
}

\author{
Ana Paula Silva Oliveira ${ }^{1}$
}

\begin{abstract}
Resumo: O objetivo deste artigo é realizar uma articulação entre a memória e o cinema documentário a partir do conceito de cinécriture criado pela cineasta Agnès Varda. Sob essa perspectiva, será analisado o filme Ulysse (1982), curta-metragem que evidencia o diálogo entre a memória, a fotografia e o cinema. Para tal, este artigo reflete sobre a cinécriture sob dois aspectos: a singularidade da imagem e do pensamento e o cinema documentário como uma narrativa de devir.
\end{abstract}

Palavras-chave: Agnès Varda, cinécriture, fotografia, memória.

\begin{abstract}
This paper aims to think the articulations between memory and cinema, in order to analize the concept "cinécriture" in the film Ulysse (1982) by Agnès Varda. Throughout this article, the cinécriture is understood under two aspects: the singularity of image and thought and the documentary filmmaking as becoming narrative.
\end{abstract}

Keywords: Agnès Varda, cinécriture, memory, photography.

\section{Introdução}

O objetivo deste artigo é, a partir da relação entre a memória, o cinema e a fotografia, refletir sobre o filme Ulysse (1982), dirigido por Agnès Varda. Entendido como um gesto de testemunho, este curta-metragem evidencia o diálogo entre o cinema e a memória, pois capta as recordações de um determinado período da vida da diretora tendo como ponto de partida uma única foto. Por meio deste processo, é possível notar a memória como um campo de batalhas em que há uma disputa entre diferentes lembranças.

Neste percurso, o trabalho ganha vários movimentos. No primeiro deles, é realizada uma explanação breve sobre a vida e obra de Varda com destaque para a sua atuação como fotógrafa. O movimento seguinte enfatiza a relação entre a memória e o esquecimento no filme. Na sequência, é destacado um conceito-chave para entender esta articulação existente entre a memória, a fotografia e o cinema nesta obra: a cinécriture, entendida como uma escrita cinematográfica singular em que predomina a autobiografia. Conforme um dos comentários em off da diretora presentes no documentário, "Ulisses é uma curiosa

\footnotetext{
${ }^{1}$ Pós-doutoranda, professora colaboradora e bolsista CAPES do programa de mestrado em Comunicação no Centro de Educação, Comunicação e Artes da Universidade Estadual de Londrina. Doutora em Filosofia pela Universidade do Porto, Portugal. Mestre em Comunicação e Semiótica pela PUC-São Paulo.
} 
experiência. É sobretudo a autobiografia das filmagens de Ulisses que transparece em filigrana: como uma reflexão sobre o cinema e a memória".

Sob essa perspectiva, analisar o filme Ulysse a partir da cinécriture, entendida como um fluxo de pensamento escrito com imagens, implica compreender a singularidade da imagem e do pensamento e entender o cinema documentário como uma narrativa de devir. Desse modo, a realizadora, como cineasta-pensadora, estabelece uma relação direta entre o cinema e o pensamento.

\title{
Os escritos sobre a película
}

Antes da carreira com cineasta, AgnèsVarda foi aluna da Escola do Louvre. Em 1948, iniciou sua carreira como fotógrafa no Teatro Nacional Popular de Paris e, com o tempo, passou a ser a fotógrafa oficial do teatro de Avignon. Com seus trabalhos nesta área, foi repórter de distintas publicações francesas. Dessa maneira, ao lançar, em 1954, no contexto da Nouvelle Vague, o filme de longa-metragem La Pointe Courte, seu nome já era reconhecido. $\mathrm{Na}$ época do lançamento, André Bazin teceu o seguinte comentário:

\begin{abstract}
Se La Pointe Courte é um filme de vanguarda, não é, contudo, no sentido tradicional da palavra, sendo este mais ou menos confundido com a herança do surrealismo ou pelo menos, com a destruição das estruturas de narração. A história que nos conta Agnès Varda é a mais simples do mundo, uma história de amor. (...). Além disso, a autora adotou no filme um ponto de vista paradoxal de estilização dentro do registro realista: tudo nele é simples e natural e, ao mesmo tempo, depurado e composto; e seus heróis dizem apenas coisas inúteis e essenciais, como as palavras que nos escapam em sonhos (BAZIN,2006, p.77).
\end{abstract}

A partir das considerações de Bazin, nota-se que, já em seu primeiro filme, Agnès Varda carrega traços que serão recorrentes durante toda a sua obra: a destruição das estruturas de narração e a simplicidade ao contar uma história. Seus filmes, assim como outros pertencentes à Nouvelle Vague, colocavam em discussão a liberdade de estilo, de modo que privilegiasse uma escrita pessoal cinematográfica.

De acordo com Varda, seu interesse pelas artes começou ainda muito jovem. Encontra o seu mote de criação na potência do acaso. Das artes, pontua três influências fundamentais em seus filmes: a interioridade de Virginia Woolf, a liberdade de tons de Cendrars e as colagens de Dos Passos. Ao contrário de seus colegas de Nouvelle Vague, ela não se formou 
junto aos cineclubes e cinematecas, pois foi criada numa família pequeno-burguesa que valorizava a poesia, o teatro e a pintura.

Depois de realizado seu primeiro filme, foi apresentada ao universo cinematográfico por Alain Resnais. Em vários depoimentos, Varda ressalta a generosidade do amigo, que foi o responsável pelo seu repertório inicial na área de cinema. Como a própria diretora afirma: "minha total ignorância dos belos filmes, muito antigos ou recentes, me permitiu ser ingênua e atrevida quando me lancei no mètier de imagem e som" (VARDA, 2006, p. 38).

\begin{abstract}
Apesar dessa espécie de marginalidade, a obra de Varda reverbera dentro do contexto da Nouvelle Vague no que diz respeito à criação de novos paradigmas para suas narrativas - a transparência do modo de narrar, a revelação do ponto de vista, a interferência do próprio realizador ou a sua participação direta dentro da narrativa. A noção do cinema como escrita, que estava sendo gestada nessa experimentação em curso, foi muito bem traduzida pelo que Alexandre Astruc chamou de "Nouvelle avant-guarde, la caméra-stylo", indicando o futuro de um cinema que podia ser pensado como uma realização concentrada no autor a um só tempo diretor/roteirista/produtor em seus "escritos diretos sobre a película" (YAKHNI, 2011, p. 19).
\end{abstract}

Em seus "escritos sobre a película", nota-se a ausência de interesses industriais e comerciais, o que permitiu à realizadora uma liberdade para transitar entre diferentes gêneros cinematográficos ao longo de sua carreira a partir de um "cinema de sensações" com um “recorte experimental". É possível notar, desde La Pointe Courte, a preocupação com um cinema à margem das demandas do mercado. Essa liberdade de criação é possível, também, pela realização de seus filmes em sua própria produtora, localizada ao lado da casa onde mora.

\title{
Memórias imperfeitas e lembranças de outras pessoas
}

No filme Ulysse (1982), Varda instiga o espectador a ouvir o que uma fotografia que ficou vinte e oito anos pregada na porta do armário embutido do seu ateliê tem a dizer. Entendida para além de um objeto de recepção estética, esta foto ocupa um papel central em sua trajetória como artista a ponto da própria realizadora perguntar o motivo de tamanha importância. Essa interrogação sobre o mundo a faz refletir sobre esta imagem e a provoca a fazer um filme de vinte minutos.

Nessa fotografia, tirada no ano de 1954, há, à beira mar, um homem nu de costas, uma criança sentada no centro da foto e uma cabra morta. Por meio dela, a realizadora faz uma 
reflexão poética sobre o cinema e a memória. Nesse percurso, uma questão colocada por Susan Sontag em Sobre a fotografia (2004) torna-se evidente: pensar a maneira como o fotógrafo, por trás de sua câmera, cria "um pequeno elemento de outro mundo: o mundoimagem que promete sobreviver a todos nós" (p.26).

Este "mundo-imagem" contado e criado por Varda permite, a partir de um debruçar sobre uma fotografia, pensar o processo de criação artística não como uma simples cópia mecânica da realidade, mas como uma recriação ativa em que um discurso sensível sobre o mundo é evidenciado em imagens. Nele, a realizadora captura o que surge desse encontro em busca de decifrar os diferentes mundos que esta foto abriga e, desse modo, construir um olhar sobre Ulysse e sobre ela própria.

Neste processo de construção do olhar, a recordação por meio da imagem fotográfica pode ser entendida como um processo de recriação ativa, um rastro em que gestos e olhares tornam presente um ausente. Didi-Huberman, ao compreender a imagem como um gesto que fala, olha e toca o espectador, define a memória como uma instância que não apenas acumula e retém informações, mas que também perde: “ela joga porque sabe, em primeiro lugar, que jamais saberá por inteiro o que acumula. Por isso ela se torna a operação mesma de um desejo, isto é, um repor em jogo perpétuo, 'vivo' (quero dizer inquieto), da perda” (DIDIHUBERMAN, 1998, p.115).

Nesse "jogo vivo" permanente entre o acumular e o perder, em que a realizadora utiliza a linguagem cinematográfica para refletir a respeito de sua primeira imagem fixa, Varda traça um percurso em busca dos personagens e de suas lembranças a respeito da foto. Nessa trajetória, várias memórias em confronto aparecem: as da realizadora, as de Ulysse e a de Folin, o homem nu que aparece na foto olhando para o mar. Na apresentação do filme, a realizadora aparece, em primeiro plano, com a foto ao fundo e fala a respeito do processo de criação deste curta-metragem:

\footnotetext{
Vinte e oito anos depois do nada, me vi sendo assombrada por essa imagem e de tal maneira que tive que fazer um filme. Esse filme é uma investigação, um olhar em direção ao passado. Eu reuni minhas próprias memórias, imperfeitas em mais de um ponto, algumas informações mais precisas e lembranças de outras pessoas. Comparando tudo isso, me dei conta do perigo. Podemos nos deparar com ossos. Tive algumas surpresas durante as filmagens, porque é filmando que fazemos um filme. Foi para Bienvenida, a mãe de Ulysse, que dediquei esse filme. Essa investigação, quase dolorosa, me ensinou muito sobre o que pode uma imagem nos dizer, sobre o que pode dizer a cada um de nós, e o que ela não pode dizer... ela apenas representa.
} 
Ao iniciar esse trabalho de investigação, sublinha o quanto gostava de Ulysse, o herói da Odisseia, e do garoto espanhol, figura central da foto tirada em 1954 e considerado seu modelo favorito na época. O filme começa com as lembranças da cineasta a respeito do momento da captação da fotografia acompanhadas de vários fotogramas com detalhes da fotografia.

Neste momento, aparece a imagem atual de Fouli Elia, diretor artístico da revista Elle, nu atrás de sua mesa de trabalho. Ele conversa em pé com a cineasta a respeito de quantos anos não se viam. No plano seguinte, sob a imagem dele sentado, a voz de Varda em off diz: "trouxe para você as fotos e umas pedras da praia". Ele segura as pedras, as coloca sobre a mesa, olha a foto e diz: "não lembro dessa foto. Lembro que você, frequentemente, tirava fotos de coisas mortas na praia. Lembro de um pássaro em particular. Lembro que você nos fez posar sem roupa. Você gostava disso. Não lembro mais".

E, desse modo, entre lembranças e esquecimentos, discorre sobre as suas impressões enquanto são mostradas imagens de ensaios fotográficos feitos pela cineasta quando Fouli era jovem. Curiosamente, ele olha para as fotografias e recorda somente das roupas e dos sapatos que usava e não de quem era. Nesse momento, Varda começa a questionar sobre onde estava a sua cabeça há 28 anos, quando escolheu colocar esse menino no meio da praia e no centro de uma fotografia que leva o seu nome: Ulysse. Dessa forma, a diretora introduz o personagem central da fotografia de 1954:

\footnotetext{
Ulysse Lorca é dono de uma livraria na Rue de Rivoli em Paris. Está casado com Isabelle e tem duas filhas: Irise e Aurore. Aurore tem a idade de Ulysse quando o conheci a primeira vez. Ele foi meu primeiro menino, digo, meu menino favorito. Não realmente meu menino, porque ele tinha uma mãe, Bienvenida, a quem chamávamos Bienve e um pai, Juan, albanês e republicano. Eram espanhóis, claro, exilados políticos. Dividíamos o mesmo pátio na Rue Daguerre (...). Os Lorca, a começar por Ulysse, me inspiraram com amor e muitas fotografias.
}

Enquanto o comentário em off descreve Ulysse, são mostradas fotografias da jovem cineasta Agnès Varda em diferentes ações: filmando, em seu laboratório revelando filmes, manuseando uma grande câmera fotográfica no pátio onde morava, além de mostrar fotos que tirou dos vizinhos, de Ulysse e de sua família, em 1954. Ao mostrar a mesma foto que havia mostrado para Fouli anteriormente, Ulysse afirma não lembrar de nada e diz que a sua única lembrança a respeito desta foto é de vê-la colada na parede do ateliê de Varda. 
O silêncio de Ulysse sobre as suas fotos de infância causa um certo estranhamento. Tanto o seu esquecimento quanto o de Fouli podem ser pensados como "pivô narrativo" dentro da narrativa fílmica. De acordo com Ferreira (2003), esse pivô é caracterizado por uma falha da memória e “esse 'branco’ pode ser menos acidente do que episódio criador” (p.92). Sublinha vários tipos de esquecimento que acontecem na poesia e no conto popular e que são relevantes para discutir a forma como o esquecimento aparece na narrativa do filme Ulysse:

Há o esquecimento profundo, a incapacidade absoluta de lembrar, aquilo que se esgarça, se perde ou por algum motivo se sepulta, não deixando que emerja para a narrativa, e há o que desliza, sob os mais diversos pretextos, nas sequências narrativas, situações em que se mascaram, eufemizam ou simplesmente se omitem fatos ou passagens (FERREIRA,2003,p.92).

Neste movimento de deslizar, evidencia-se um ato de criação em que o esquecimento não é o par opositivo da memória, mas, em conjunto com ela, passa a ser fundamental para a construção da narrativa: Nesse caso, como pontua Ferreira(2003), lembrar é um processo, uma razão de ser, um fluxo que torna o esquecimento o pivô do que será desenvolvido e, desse modo, permite "a transformação".

\section{A cinécriture como escrita cinematográfica singular}

Neste filme, Varda constrói um diário íntimo em que suas experiências de vida como fotógrafa encontram-se com as experiências da cineasta. Por meio de um processo subjetivo e afetivo e a partir da construção de um cinema feito com poucos recursos, poucos efeitos e poucos equipamentos que potencializam a linguagem do documentário, utiliza a cinécriture para modular a forma do ensaio. Em seu modo ensaístico de criação, a diretora apresenta características singulares, o que torna possível refletir sobre a sua escrita cinematográfica a partir da noção de ensaio discutida por Adorno no artigo "O ensaio como forma" (2006).

Ao pensar o ensaio na literatura alemã, Adorno salienta o caráter fragmentário pois, uma vez que a própria realidade é fragmentada, o ensaio pensa em fragmentos e encontra a sua unidade ao buscar, através das fraturas, a realidade. Para Adorno, "a descontinuidade é essencial ao ensaio; seu assunto é sempre um conflito em suspenso" (ADORNO, 2003,p.35). O autor sublinha que no ensaio não há construção de "nenhum andaime ou estrutura", pois, mesmo reunidos num todo legível, os seus elementos apresentam-se separados entre si, 
embora discretamente. No entanto, estes elementos são cristalizados por seu movimento e, desse modo, criam um "campo de forças".

Escreve ensaisticamente quem compõe experimentando: quem vira e revira o seu objeto, quem o questiona e o apalpa, quem o prova e o submete à reflexão; quem o ataca de diversos lados e reúne no olhar de seu espírito aquilo que vê, pondo em palavras o que o objeto permite vislumbrar sob as condições geradas pelo ato de escrever (ADORNO, 2006, p.36).

Ao virar e revirar uma fotografia antiga, Varda traça um percurso em busca dos personagens e de suas lembranças a respeito da foto. Nesse caminho, várias memórias em confronto aparecem: as da realizadora, as de Ulysse e a de Folin, o homem nu que aparece na foto olhando para o mar. Sob essa perspectiva, a cinécriture pode ser pensada para além de um método de trabalho. É uma escrita íntima, em que indivíduos singulares elaboram os sentidos da sua própria experiência ao mesmo tempo que o relato das aventuras da cineasta confirma a sua experiência do mundo, de vida e de si. Dessa maneira, o ensaio relacionado com a experiência, com a escrita do eu, com o conhecimento e com a experimentação da linguagem evidencia um trabalho de memória em que a narrativa

\footnotetext{
mergulha as coisas na vida do narrador para depois as ir aí buscar de novo. Por isso a narrativa tem gravadas as marcas do narrador, tal como o vaso de barro traz as marcas da mão do oleiro que o modelou. É tendência dos narradores começar as suas histórias com a descrição das condições em que tomaram conhecimento do que se segue, quando não as fazem passar, pura e simplesmente, por histórias vividas por eles próprios (BENJAMIM, 1996, p.37).
}

Nesse mergulho, ao compreender os seus pensamentos como imagens, Varda evidencia momentos singulares do início de sua carreira como cineasta no ano de 1954 e "vai colher aquilo que narra à experiência, seja própria ou relatada. E transforma-a por vezes em experiência daqueles que ouvem a sua história" (BENJAMIN, 1996,p.32). Dessa maneira, Varda evidencia a cinécriture como uma escrita criadora feita com imagens e abre possibilidades de discussão do modo como o ensaio pode realizar uma recriação a partir das imagens que o compõem.

Sendo assim, torna-se necessário compreender a maneira pela qual as imagens são inscritas no ensaio bem como o fluxo do pensamento que geram. Sob esta perspectiva, são abertos caminhos para a discussão da singularidade da imagem e do pensamento e o cinema documentário como uma narrativa de devir. 


\section{As singularidades da imagem e o pensamento}

Pensar o documentário Ulysse a partir da relação entre o cinema e a memória implica, num primeiro momento, compreender a singularidade da imagem e a sua relação com o pensamento. Para Deleuze, as imagens cinematográficas têm um movimento contínuo de ação, reação, produção e consumo umas sobre as outras e, do ponto de vista da sua gênese e da sua composição, podem ser entendidas como signos.

O cinema documentário, ao ser entendido como uma experiência sígnica em que a produção de signos vai muito além da simples interpretação, é formado por imagens singulares, signos que exigem uma decodificação específica e o tornam uma máquina "capaz de funcionar efetivamente, produtora de signos de diferentes ordens, que deve ter um efeito, no caso, sobre o espectador" (DELEUZE, 1964, p. 5).

Dessa forma, entender o signo como uma imagem, num primeiro momento, implica compreendê-lo a partir da relação entre o signo e o pensamento. Na obra Proust et les Signes (1964), Deleuze estabelece essa relação ao analisar a estrutura da obra $A$ la recherche $d u$ temps perdu de Marcel Proust. O autor evidencia como a experiência da escritura da obra mobiliza o involuntário e o inconsciente, considerados procedimentos próprios do sentido e que são mobilizados por uma experiência sígnica responsável por reger a interpretação, considerada como o reverso da produção dos próprios signos:

A obra de arte não se limita a interpretar ou emitir signos por interpretar; ela os produz mediante determinados procedimentos. O próprio Proust concebe a sua obra como um instrumento ou uma máquina capaz de funcionar de maneira eficaz, produtora de signos de diferentes gêneros que devem provocar um efeito sobre o leitor (DELEUZE, 1964, p. 5).

Em seu processo de criação de uma escrita cinematográfica construída como um ensaio, Varda provoca um efeito no espectador de não pensar o filme Ulysse como um conjunto de afirmações de verdades. De acordo com ela, "o filme propõe pensamentos, o filme faz pensar, o filme diz". Dessa forma, este filme pode ser compreendido como "uma forma que pensa, se pensa, se ensaia e se experimenta; um meio de expressão em que a matéria se modula juntamente com o pensamento" (SIQUEIRA, 2006, p. 24).

Nesse processo, Agnès Varda se aproxima da problemática deleuziana da potência do falso, entendida como um princípio de produção de imagens. Essa questão é evidenciada na 
cena final do filme num diálogo entre a realizadora e Bienvenida, mãe de Ulysse e pessoa para quem a realizadora dedicou o filme. Nela, Varda pergunta por que escolheu esse nome para o seu filho, ao que Bienvenida responde que o pai queria muito e gostava desse nome: "Juan quis esse nome. Quando fui registrá-lo como Ulysse e o nome não aparecia no calendário católico não deixaram. Tivemos que chamá-lo de Antônio, como seu avô".

A partir deste momento, é evidenciada uma conexão entre o ensaio e o pensamento e é possível ouvir ressoar a frase de Varda "o que pode uma imagem dizer e o que pode nos dizer... ela apenas representa". Desse modo, a realizadora enfatiza o ensaio como um gênero que "se revolta contra a obra maior", põe em xeque o modo clássico de fazer documentário e evidencia o cinema documentário como uma narrativa de devir.

\section{O cinema documentário e a narrativa de devir}

O cinema documentário como uma narrativa de devir pode ser entendido como um processo em que a realizadora e as personagens se tornam diferentes do que são pois, a cineasta tem de se tornar outra, ao mesmo tempo em que as personagens têm de devir elas próprias outras. O devir é um verbo e deve ser considerado em toda a sua consistência, pois não pode ser reduzido e nem remeter aos verbos "produzir", “equivaler", "ser" ou "parecer". Para Deleuze (1985), o devir é a vontade de potência, a potência do falso e da vida.

\footnotetext{
Devir não é imitar, nem fazer como se, nem se conformar a um modelo, seja de justiça ou de verdade. Não há um termo do qual se parta, nem ao qual se chegue, ou ao qual se deva chegar. Não se trata também de dois termos que trocam de posição (...). Pois, à medida que alguém se torna, aquilo que ele se torna muda tanto quanto ele. Os devires não são fenômenos de imitação, nem de assimilação, mas de dupla captura, de evolução não paralela, núpcias entre dois reinos (DELEUZE, 1996, p. 8).
}

Nesta dupla captura realizada pelo filme Ulysse, é possível notar esses devires das personagens, da realizadora e a combinação entre eles e, dessa maneira, pensar num movimento de fabulação em que as personagens, incessantemente, atravessam a fronteira entre o real e a ficção. No cinema documentário, entender a fabulação da personagem implica um direcionamento que tem por objetivo não eliminar a ficção, mas libertar a personagem de um modelo de verdade, permitindo a criação de uma "função de fabulação" que se opõe a esse modelo. 
Nesse contexto, não é necessário que a cineasta tenha que inventar ela própria uma ficção, pois tem a possibilidade de se atribuir "intercessores", ou seja tomar personagens nãofictícias, reais e fazer com que elas próprias entrem em estado de "fabular", "fazer lenda", "ficcionar". É o que notamos em Fouli, Ulysse e Bienvenida. Nesse sentido, há um duplo devir, pois as personagens dão um passo na direção da realizadora, da mesma maneira que Varda dá um passo na direção delas. Ao atravessar fronteiras e passagens, Ulysse, Fouli e Varda inventam e quanto melhor inventam, mais reais parecem ser.

\section{Considerações finais}

No filme Ulysse (1982) a realizadora, ao revelar as suas lembranças a partir de uma fotografia tirada em 1954, faz vir à tona diversas histórias que trazem em si um trabalho de reconstrução das suas próprias lembranças além das de Fouli e de Ulysse. Ao olhar para o passado, é como se cada uma das personagens recriasse os fatos vividos no presente o que permite que o acontecimento seja presentificado e o esquecimento torne-se um "pivô narrativo", entendido como um ato de transformação da narrativa.

Desse modo, é possível evidenciar que o gesto de criação deste ensaio cinematográfico realiza um movimento que possibilita tanto para Varda quanto para as outras personagens reviverem e testemunharem a sua própria experiência. A realizadora evidencia que não se trata apenas de esquecer o passado, mas também de agir sobre o presente. Ao transmitir essa experiência tecida "na substância da vida vivida", mostra a possibilidade de estabelecer uma relação entre a infinitude do acontecimento lembrado e a finitude do acontecimento vivido, pois "um acontecimento vivido é finito, ou pelo menos encerrado na esfera do vivido, ao passo que o acontecimento lembrado é sem limites, porque é apenas uma chave para tudo o que veio antes e depois" (BENJAMIN, 1996, p. 37).

Neste contexto, tanto a fotografia por meio da qual é possível refletir sobre o processo de recriação das recordações que afloram e emergem a partir das imagens, quanto o documentário, compreendido como um testemunho indireto, uma maneira de registrar depoimentos sobre um acontecimento, e também como um modo de escrita e interpretação da história de um lugar podem ser entendidos como um espaço de reflexão sobre a relação entre a memória, o cinema e a fotografia. 


\section{Referências}

ADORNO, Theodor W. O ensaio como forma. In: ADORNO, Theodor W. Notas de literatura I. São Paulo: Editora 34, 2003. p. 15-45.

BAZIN, André. "Le Parisien Libere", 7 de janeiro de 1956. In: Retrospectiva Agnès Varda - o movimento perpétuo do olhar (Catálogo). Centro Cultural Banco do Brasil, 2006, p. 77.

BENJAMIN, Walter. Magia e técnica, arte e política - Obras escolhidas 1. São Paulo: Ed. Brasiliense, 1996.

DELEUZE, Gilles.Proust et les signes. Paris: Presses Universitaires de France, 1971

Cinéma 2. L’image-temps. Paris: Les Éditions de Minuit, 1985.

Dialogues. Paris: Flammarion, 1996.

; GUATTARI, Felix . “Mil platôs, volume 1. São Paulo: Editora 34, 1995.

DIDI-HUBERMAN, Georges. O que vemos, o que nos olha. São Paulo: Editora 34, 1998.

FERREIRA, Jerusa Pires. Armadilhas da memória e outros ensaios. Cotia, São Paulo: Ateliê Editorial, 2003.

RENOV, Michael. Investigando o sujeito: uma introdução. In: MOURÃO, Maria Dora; LABAKI, Amir (Org.). O cinema do real. São Paulo: Cosac \& Naify, 2005. p. 234-257. RETROSPECTIVA Agnès Varda, o movimento perpétuo do olhar. Centro Cultural Banco do Brasil. São Paulo, 2006.

SIQUEIRA, Marília Rocha de. O ensaio e as travessias do cinema documentário. 2006. 188f. Dissertação (Mestrado em Comunicação Social) - Faculdade de Filosofia e Ciências Humanas, Universidade Federal de Minas Gerais.

VARDA Agnès: Os filmes e as fotografias. Catálogo realizado por ocasião do ciclo cinematográfico e da exposição: Agnès Varda: Os filmes e as fotografias. Lisboa: Cinemateca Portuguesa, 1993.

YAKHNI, Sarah. Cinensaios de Varda: o documentário como escrita para além de si. 2011.212f. Tese (Doutorado em Multimeios) - Instituto de Artes, UNICAMP.

\section{Filmografia}

VARDA, AGNÈS. Ulysse. 1982, cor, 35 mm, 22 min. 